\title{
AS COMPETÊNCIAS GERENCIAIS DESENVOLVIDAS PELOS SECRETÁRIOS EXECUTIVOS
}

\section{MANAGEMENT SKILLS DEVELOPED BY EXECUTIVE SECRETARIES}

\section{Conceição de Maria Pinheiro Barros}

Doutoranda em Educação pela Universidade Estadual do Ceará - UFC

Professora do Departamento de Administração da Universidade Federal do Ceará - UFC e Vicecoordenadora do Curso de Secretariado Executivo da Universidade Federal do Ceará - UFC E-mail: conceicaompb@yahoo.com.br (Brasil)

\section{Joelma Soares da Silva}

Mestre em Administração da Universidade Estadual do Ceará - UECE

Professora do Departamento de Administração e coordenadora do Curso de Secretariado Executivo da Universidade Federal do Ceará - UFC

E-mail: joelma.soares@ufc.br (Brasil)

\section{Geovana Alves de Lima}

Bacharel em Secretariado Executivo pela Universidade Federal do Ceará - UFC

E-mail: ge_lalves@hotmail.com (Brasil)

\section{Daniela Graciela Silva Brito}

Graduação em Secretariado Executivo pela Universidade Federal do Ceará - UFC Assistente em Administração da Universidade Federal do Ceará - UFC

E-mail: danielabrito28@gmail.com (Brasil) 


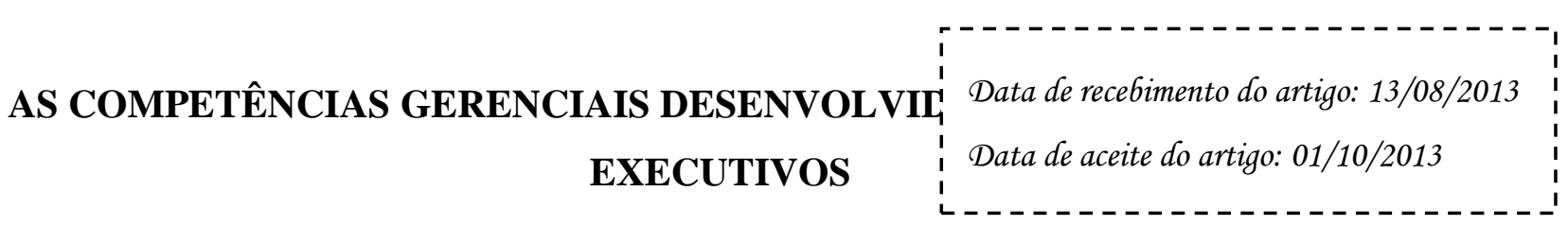

\section{RESUMO}

O profissional de Secretariado Executivo está diretamente envolvido nos processos de gestão da empresa, pois sua atuação se dá em cargos de assessoria a diretores, gerentes, supervisores, assim como em cargos específicos de gestão, como assistente administrativo, responsável pelo departamento, coordenador do setor, consultor secretarial entre tantas outras nomenclaturas existentes. Este trabalho tem como objetivo geral identificar as competências gerenciais desenvolvidas por uma amostra de secretários executivos no exercício da profissão. Para o alcance do objetivo proposto foi realizada uma pesquisa quantitativa, a partir de um levantamento bibliográfico e uma pesquisa de campo. Após a análise dos dados constatou-se que as competências gerenciais são utilizadas em Secretariado Executivo nas suas diversas responsabilidades, contribuindo para o alcance de objetivos e metas organizacionais por meio do desenvolvimento de atividades que envolvem o gerenciamento, participação no planejamento, na condução e estímulo às pessoas e ao controle. Esse profissional vem superando grandes desafios, ampliando suas competências e seu campo de inserção e contribuindo efetivamente para o bom desempenho organizacional.

Palavras-chave: Competências Gerenciais; Gestão em Secretariado; Competências Gerenciais do Secretário Executivo.

\section{MANAGERIAL SKILLS DEVELOPED BY EXECUTIVE SECRETARIES}

\begin{abstract}
The Executive Secretaries are directly involved in management processes of the company because their work takes place in advisement positions with directors, managers, supervisors, as well as specific management positions such as manager assistant, in charge of department, section coordinator, consultant secretarial and many other existing nomenclatures. This study aims at investigating the managerial skills developed by sample of Executive Secretaries. In order to achieve the purpose was carried out a quantitative study, based on a bibliographic survey and field research. After data analysis it was noticed that management skills are used in the Executive Secretariat area in its various responsibilities, contributing to the achievement of objectives and organizational goals through the development of activities that involve management, participation in planning, conducting and encouraging people and in control. This work has been overcoming challenges and increasing their skills and their field of integration and contributing effectively to a good organizational performance.
\end{abstract}


Keywords: Managerial Skills; Management; Managerial Skills of the Executive Secretariat. 1 INTRODUÇÃO

O profissional de Secretariado Executivo está diretamente envolvido nos processos de gestão da empresa, conforme apontam estudiosos da área ao abordar a sua atuação como gestor (Lasta e Durante, 2008; Barros, Braga e Silva, 2011). Nesse contexto, percebe-se o surgimento de estudos voltados para um novo desafio: a gestão secretarial. No entanto, as pesquisas sobre essa temática ainda são limitadas no sentido de delinear conceitos, áreas, atividades e formas de atuação da gestão em Secretariado. Considera-se que essa discussão perpassa estudos sobre gerenciamento, bem como as competências gerenciais necessárias a sua atuação.

Dessa forma, chegou-se ao seguinte questionamento: como são utilizadas as competências gerenciais na atuação do profissional de Secretariado Executivo? Este trabalho tem como objetivo geral investigar as competências gerenciais na atuação do Secretário Executivo na visão dos profissionais fundamentando-se nas aptidões propostas nos papéis gerenciais de Quinn, Faerman e Thompson (2003) e, como objetivos específicos, identificar as atividades de gerenciamento na atuação secretarial e averiguar quais são as competências gerenciais utilizadas na atuação do secretário executivo.

Para o alcance dos objetivos propostos foi realizada uma pesquisa de natureza quantitativa, a partir de um levantamento bibliográfico e uma pesquisa de campo, tendo como fundamentação teórica as proposições de Quinn et al. (2003), as quais apresentam as competências gerenciais a partir de oito papéis fundamentais: mentor, facilitador, monitor, coordenador, diretor, produtor, negociador e inovador, relacionando-os com a atuação secretarial.

\section{GESTÃO, COMPETÊNCIAS GERENCIAIS E O PROFISSIONAL DE SECRETARIADO EXECUTIVO}

A gestão é um tema abrangente que vem ganhando espaço no meio secretarial. $O$ profissional de Secretariado Executivo tem se desenvolvido e evoluído a ponto de não mais executar somente as atividades técnicas inerentes ao cargo. Têm-se profissionais executando as mais diversas atividades incluindo-se as atividades de gestão. Com base nisso, torna-se imperativo o

Revista de Gestão e Secretariado - GeSec, São Paulo, v. 4, n. 2, p 25-47, jul./dez. 2013. 
estudo das competências gerenciais desses profissionais, no campo de atuação, partindo do princípio de que eles estão atuando como gestores.

\subsection{O PROCESSO DE GESTÃo $E$ AS COMPETÊNCIAS GERENCIAIS NA PERSPECTIVA DE QUINN, FAERMAN E THOMPSON}

A gestão é desempenhada nas organizações por profissionais que possuem conhecimento técnico, espírito de liderança e visão holística da empresa com o intuito de possibilitar o funcionamento de uma área administrativa. A função de gestão exige o desenvolvimento de planejamento, organização, liderança, controle e tomada de decisões (Quinn et. al.2003).

Segundo Ferreira (2001, p. 374) gestão é o "ato ou efeito de gerir". Gerir, por sua vez, segundo o mesmo autor, é ter gerência sobre algo, administrar negócios, recursos e pessoas. Segundo Quinn et al. (2003), ao discutir o processo gerencial, é conveniente e também necessário descrever e estudar cada função do processo separadamente. No entanto, como resultado, poderia parecer que o processo gerencial é uma série de funções separadas, cada uma delas encaixadas ajustadamente a um compartimento a parte. Na prática, um gerente pode, e isso ocorre com frequência, executar simultaneamente, ou ao menos de forma continuada, todas ou algumas das seguintes quatro funções, conforme Quinn et al. (2003):

a) Planejamento: é o início da gerência (do ato de gerenciar). Primeiramente, deve-se verificar a situação em termos externos, os fatores sobre os quais não se tem controle e que afetam a organização, e internos, condições atuais.

b) Organização: criar órgãos é definir as atividades a executar, agrupá-las em cargos, definir quem faz cada uma delas, formalizar autoridade e responsabilidades, traçar linhas de comunicação entre os cargos e tornar claras normas e regras para um trabalho eficiente.

c) Direção: para o trabalho ser eficiente (relação custo/benefício) as pessoas precisam ver sentido no que estão fazendo. Elas precisam de desafio e confiança, por parte da gerência. Motivação, clima de trabalho adequado, espírito de equipe é o que as pessoas precisam para acreditar nos objetivos propostos. Tem relação com liderança, satisfação e motivação no trabalho.

d) Controle: plano feito, boa organização, clima adequado, mas o fundamental é o acompanhamento completo de todas as tarefas anteriores para que os objetivos sejam atingidos.

Revista de Gestão e Secretariado - GeSec, São Paulo, v. 4, n. 2, p 25-47, jul./dez. 2013. 
Com relação ao conceito de competência, conforme Fleury e Fleury (2001, p. 184) “é uma palavra do senso comum, utilizada para designar uma pessoa qualificada para realizar alguma coisa." Na perspectiva de Quinn et. al. (2003), as competências gerenciais são aquelas nas quais os gerentes devem adquirir diferentes capacidades para transpor os desafios organizacionais. Quinn $e t$ al. (2003, p.16) realizaram um estudo com gerentes e chegaram à seguinte conclusão: “[...] a complexidade comportamental, tal como avaliada pelo superior de cada gerente, guardava relação com a eficácia gerencial geral do indivíduo, tal como avaliada por subordinados seus". A partir dessa pesquisa os citados autores definiram oito papéis gerenciais e suas competências específicas, conforme figura 1:

Figura 1 - As competências e os papéis dos líderes no quadro de valores competitivos.

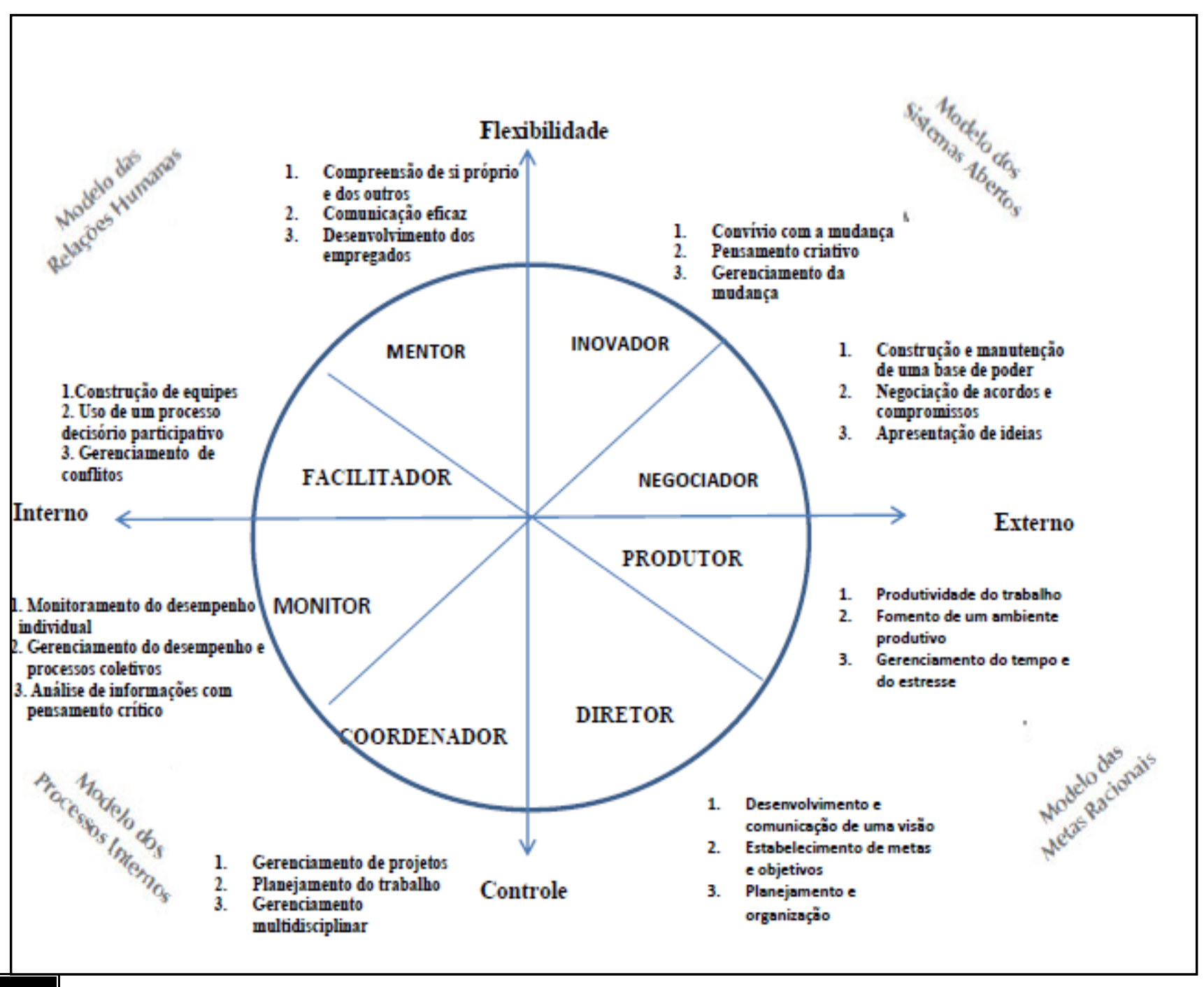

Revista de Gestão e Secretariado - GeSec, São Paulo, v. 4, n. 2, p 25-47, jul./dez. 2013. 
Fonte: Quinn et al. (2003, p. 17).

Tendo como base a figura 1 de Quinn et al. (2003), pode-se subentender que: no papel de diretor, o profissional menciona as expectativas organizacionais por meio de processos, define problemas e seleciona opções, gera regras e dá instruções; do papel de produtor, espera-se que o profissional direcione-se para a tarefa com foco no trabalho e exiba alto grau de interesse, motivação, energia e ousadia pessoal; do papel de monitor, supõe-se que o profissional saiba o que se passa em sua área de atuação, com o intuito de determinar se as pessoas estão cumprindo as regras e verificar se o setor está fazendo sua parte, dessa forma, o monitor é um analista; do papel de coordenador, o profissional oferece apoio e estrutura ao fluxo do sistema, para isso, é fundamental que o gerente seja digno de confiança e crédito (Quinn et al.. 2003).

Conforme a figura de Quinn et al. (2003), no papel de facilitador, é pertinente que o profissional promova esforços coletivos, possibilite a coesão e o trabalho em equipe e administre conflitos interpessoais. É essencial que se utilizem técnicas que contribuam para a solução de conflitos e que favoreçam a colaboração e a participação das pessoas envolvidas; no papel do mentor, a expectativa é de que o profissional se oriente ao desenvolvimento dos colaboradores, por meio da orientação cuidadosa e empática. O mentor deve ser solícito, atencioso, afável, aberto e justo, escutando reivindicações, transmitindo apreciação e distribuindo elogios e reconhecimento; no papel de inovador, o profissional deve ser responsável por facilitar a adaptação e a mudança, devendo, para isso, focalizar o ambiente em constantes transformações, identificar tendências, conceituar e projetar mudanças necessárias; do papel de negociador, espera-se que, junto ao papel de inovador, que o profissional possa vislumbrar mudanças e uma maneira melhor de realizar as atividades, apresentar e negociar as ideias com eficácia.

Quinn et al. (2003) enfatizam que os gerentes devem adquirir diferentes competências para galgar novos patamares na organização. Tais competências estão relacionadas a cada um dos oito papéis citados na Figura 1. O Quadro 1 sintetiza os papéis, as competências e as características propostas por Quinn et. al. (2003).

Revista de Gestão e Secretariado - GeSec, São Paulo, v. 4, n. 2, p 25-47, jul./dez. 2013. 


\begin{tabular}{|c|c|c|}
\hline PAPEL & COMPETENNCIAS & CARACTERÍSTICAS \\
\hline \multirow{5}{*}{ MENTOR } & \multirow{2}{*}{$\begin{array}{l}\text { Compreensão de si mesmo e } \\
\text { dos outros. }\end{array}$} & $\begin{array}{l}\text { Autocompreensão fundamenta-se no modelo dos cinco } \\
\text { fatores no indicador de tipos de Myers-Briggs. }\end{array}$ \\
\hline & & $\begin{array}{c}\text { Capacidade de expandir a sua própria conscientização } \\
\text { de tudo aquilo que menos deseja saber a seu próprio } \\
\text { respeito }\end{array}$ \\
\hline & Comunicação eficaz. & $\begin{array}{l}\text { Informar, coordenar e motivar os colaboradores de } \\
\text { forma eficaz. }\end{array}$ \\
\hline & \multirow{2}{*}{$\begin{array}{l}\text { Desenvolvimento dos } \\
\text { empregados. }\end{array}$} & Delegação de responsabilidades. \\
\hline & & Avaliação de desempenho \\
\hline \multirow{3}{*}{ FACILITADOR } & Construção de equipes. & Transformar grupos em equipes \\
\hline & Tomada de decisões & Participação dos funcionários no processo decisório \\
\hline & Gerenciamento de conflitos. & $\begin{array}{l}\text { Administrar situações de conflitos no cotidiano do } \\
\text { ambiente de trabalho. }\end{array}$ \\
\hline \multirow{3}{*}{ MONITOR } & $\begin{array}{l}\text { Administração de } \\
\text { informações }\end{array}$ & $\begin{array}{l}\text { Administrar as informações recebidas por meio do } \\
\text { pensamento crítico. }\end{array}$ \\
\hline & $\begin{array}{c}\text { Administração de sobrecarga } \\
\text { de informações. }\end{array}$ & Considerar as informações úteis. \\
\hline & $\begin{array}{l}\text { Administração dos processos } \\
\text { essenciais. }\end{array}$ & $\begin{array}{l}\text { Identificar os principais fatores que indicam o grau de } \\
\text { eficácia de processo. }\end{array}$ \\
\hline COORDENADOR & Gerenciamento de projetos. & Planejamento e monitoramento. \\
\hline
\end{tabular}




\begin{tabular}{|c|c|c|}
\hline & Planejamento do trabalho. & Reestruturação do trabalho. \\
\hline & $\begin{array}{l}\text { Gerenciamento } \\
\text { multifuncional. }\end{array}$ & Gerenciar as equipes de trabalho. \\
\hline \multirow{3}{*}{ DIRETOR } & $\begin{array}{l}\text { Desenvolvimento e } \\
\text { comunicação de uma visão. }\end{array}$ & $\begin{array}{c}\text { Comunicação para uma visão de forma eficaz nos } \\
\text { níveis estratégico, tático e operacional. }\end{array}$ \\
\hline & $\begin{array}{l}\text { Estabelecimento de metas e } \\
\text { objetivos. }\end{array}$ & Determinar as metas e os objetivos organizacionais. \\
\hline & Planejamento e organização. & Planejar e ordenar o trabalho a ser desenvolvido. \\
\hline \multirow{4}{*}{ PRODUTOR } & Trabalho produtivo. & Definição de metas. \\
\hline & $\begin{array}{l}\text { Fomento a um ambiente de } \\
\text { trabalho produtivo }\end{array}$ & Possibilitar recompensa e motivação. \\
\hline & \multirow[b]{2}{*}{$\begin{array}{l}\text { Administração do tempo e } \\
\text { do estresse/ equilíbrio de } \\
\text { demandas concorrentes. }\end{array}$} & $\begin{array}{c}\text { Gerenciar o estresse afeta a motivação dos } \\
\text { funcionários. }\end{array}$ \\
\hline & & $\begin{array}{l}\text { Administração do tempo por meio do planejamento e } \\
\text { estabelecimento de prioridades. }\end{array}$ \\
\hline \multirow{3}{*}{ NEGOCIADOR } & $\begin{array}{l}\text { Construção e manutenção da } \\
\text { base do poder. }\end{array}$ & Influenciar colaboradores, superiores e pares. \\
\hline & $\begin{array}{l}\text { Negociação de acordos, } \\
\text { compromissos e } \\
\text { apresentação de ideias. }\end{array}$ & Capacidade de manter o diálogo. \\
\hline & Apresentação de ideias. & Focalizar o objetivo, a audiência e os recursos. \\
\hline \multirow{4}{*}{ INOVADOR } & \multirow{2}{*}{ Convívio com a mudança. } & Aceitar as mudanças. \\
\hline & & $\begin{array}{l}\text { Influenciar o fluxo de energia e recursos disponíveis } \\
\text { reservados para determinadas metas. }\end{array}$ \\
\hline & Pensamento criativo. & Criar novas ideias e soluções. \\
\hline & Gerenciamento da mudança. & Ser flexível às mudanças. \\
\hline
\end{tabular}


Quadro 1- Síntese dos papéis, competências e suas características a partir de Quinn et. al. (2003). Fonte: Adaptado de Quinn et al. (2003).

Na proposição de Quinn et al. (2003) no papel de mentor, o gerente deve desenvolver as competências: a) compreensão de si mesmo: compreende a autocompreensão e fundamenta-se no modelo dos cinco fatores (grau de neurose, extroversão, receptividade a novas experiências, agradabilidade, conscienciosidade), no indicador de tipos de Myers-Briggs (introversão/extroversão, sensação/intuição e pensamento/sentimento); quanto à compreensão dos outros, é necessário que o gerente seja capaz de expandir a sua própria conscientização de tudo aquilo que menos deseja saber a seu próprio respeito; b) comunicação eficaz: o processo de comunicação dever ser utilizado para informar, coordenar e motivar os colaboradores de forma eficaz, buscando dirimir os obstáculos na sua execução; c) desenvolvimento dos empregados ocorre por meio de duas abordagens: a delegação, que visa ao aprimoramento das competências e habilidades dos colaboradores, possibilitando-lhes oportunidades para assumirem novas responsabilidades e a avaliação de desempenho, a qual tem o intuito de oferecer aos empregados o feedback acerca de seu desempenho, facilitando o aprimoramento dos colaboradores e melhorando o fluxo das atividades.

Para Quinn et al. (2003), no papel de facilitador o gerente necessita das competências: a) construção de equipes: o gerente deve empenhar esforços para que um grupo de pessoas se transforme em uma equipe de trabalho; b) uso da tomada participativa de decisões: na gestão participativa os funcionários têm a oportunidade de contribuir com as decisões organizacionais; administração de conflitos: os conflitos podem ter consequências positivas ou negativas.

Para o papel de monitor, Quinn et al. (2003) destacam as seguintes competências: a) monitoramento do desempenho individual: tem o intuito de monitorar o desempenho individual dos colaboradores a fim de que as atividades sejam realizadas, trazendo resultados para a organização; b) gerenciamento do desempenho e processos coletivos: visa a administrar os processos essenciais, ou seja, aqueles que agregam valor ao produto ou serviço da organização; c) administração de informações por meio de pensamento crítico: as informações e as ideias devem ser apresentadas com clareza e conter o máximo de informações de forma crítica e objetiva em uma linha de raciocínio lógico.

As competências do papel de coordenador, segundo Quinn et al. (2003), são: a) gerenciamento de projetos: envolve o planejamento; definir quais os pré-requisitos do trabalho, 
o volume de trabalho, os recursos de trabalho e o monitoramento de projetos; b) planejamento do trabalho: os autores destacam duas vertentes na reestruturação do trabalho: foco no cargo individual e foco em grupos de trabalho autogerenciados; c) gerenciamento multifuncional: gerenciamento das equipes de trabalho tendo por diretrizes básicas esclarecimento de metas e a declaração de missão, criação de massa crítica de liderança, manutenção da equipe por meio da responsabilidade do desempenho coletivo, manutenção da equipe multifuncional, fornecimento de informações relevantes, treinamento dos envolvidos e gerenciamento de processos.

Para o papel de diretor as competências necessárias, conforme Quinn et al. (2003), são: a) desenvolvimento e comunicação de uma visão: o gerente deve ajudar aos demais a enxergar o que há a sua frente, a partir do seu foco, por meio da comunicação para uma visão de forma eficaz nos níveis estratégico, tático e operacional; b) estabelecimento de metas e objetivos: o gerente participa da formulação de objetivos específicos, com vistas à consecução da visão, definição de metas nos diversos níveis da organização bem como da estratégia; c) planejamento e organização: o planejamento e a organização são fundamentados na visão e estratégia articuladas.

Conforme Quinn et al. (2003) o papel de produtor complementa o papel de diretor, devendo-se desenvolver as competências: a) trabalho produtivo: definição de metas, engajamento total e imersão na atividade, hipersensibilidade e consciência da atividade durante seu desenrolar e capacidade de desfrutar da experiência imediata em tempo real; b)fomento a um ambiente de trabalho produtivo: envolve o sistema de recompensa na nova economia e a motivação dos outros; c)administração do tempo e do estresse/ equilíbrio de demandas concorrentes: o estresse afeta a saúde física dos colaboradores bem como reduz a motivação e a capacidade de relacionamento com os colegas, além dos prejuízos para as organizações. Quanto à administração do tempo, é importante que se utilizem estratégias como planejamento e estabelecimento de prioridades, a fim de utilizar o tempo de forma eficiente.

O papel de negociador envolve as competências citadas a seguir, segundo Quinn et al. (2003): a) construção e manutenção da base do poder: o gerente deve ser capaz de influenciar colaboradores, superiores e pares por meio do uso de técnicas diferentes; b) negociação de acordos e compromissos: trata-se da capacidade de manter o diálogo com o intuito de solucionar divergências mediante cuidadoso compartilhamento de pontos de vista; c) apresentação de ideias: deve focalizar alguns pontos, tais como o objetivo (claro e definido), audiência (compreender o modo de conduzir a apresentação de um ponto a outro) e os recursos (preparação da apresentação).

Quanto ao papel de inovador, Quinn et al. (2003) ressaltam as competências: a) convívio com a mudança: trata-se da aceitação pessoal e do convívio com a mudança; b)pensamento criativo:

Revista de Gestão e Secretariado - GeSec, São Paulo, v. 4, n. 2, p 25-47, jul./dez. 2013. 
forma de pensar que envolve a geração de novas ideias e soluções, destacando-se três dimensões: habilidades referentes ao domínio, habilidades criativas e motivação de tarefas; c) gerenciamento da mudança: ser flexível às mudanças para que se possam alcançar os objetivos e metas organizacionais. Para os autores existem cinco tipos de mudanças capazes de provocar a resistência dos funcionários: mudanças que afetam as demandas de conhecimento e competência, mudanças associadas a perdas econômicas ou de status, mudanças sugeridas por outros, mudanças que envolvem riscos e mudanças que acarretam ruptura das relações sociais.

\subsection{REFLEXÕES ACERCA DAS COMPETÊNCIAS DO PROFISSIONAL DE SECRETARIADO EXECUTIVO}

Diante do que foi exposto em relação às competências gerenciais, apresentam-se a seguir as competências do secretário executivo. Com a transformação e o reconhecimento, o profissional antigo dá lugar a um profissional com conhecimentos ecléticos, tanto de estrutura quanto de comportamento organizacional, os quais são as bases da gestão secretarial. Assim, faz-se mister que esse profissional seja conhecedor técnico e comportamental dos objetivos da organização, conheça os principais clientes, saiba as prioridades da organização e esteja interessado em contribuir para o crescimento da empresa.

Ribeiro (2005) cita que um profissional secretário deve recordar-se sempre de regras básicas, como:

a) segurança profissional: a certeza da capacitação e o bom senso, determinados pelo equilíbrio emocional, são responsáveis pela segurança profissional;

b) ser confiável: vai além da discrição, pois é a capacidade de absorver uma tarefa e levá-la até o fim; ser amistoso: principalmente quando se trabalha com vários executivos, vários chefes;

c) ser responsável: uma característica que com certeza representa o bom desempenho do profissional competente;

d) ser leal: ser leal também à empresa, e não somente ao executivo; ser sincero: trabalhar com a verdade;

e) ser cooperador: a capacidade de cooperar é fundamental ao trabalho de uma equipe que se constrói no "fazer diário";

Revista de Gestão e Secretariado - GeSec, São Paulo, v. 4, n. 2, p 25-47, jul./dez. 2013. 
f) ter mente aberta: é preciso aprender a ter equilíbrio no julgamento, para não assumir uma postura antiprofissional de um juiz arbitrário e inflexível;

g) ser estável: manter o equilíbrio e assim, trabalhar com o bom senso acima de tudo;

h) ter capacidade de comunicação: o circuito comunicativo é pré-requisito para assegurar o sucesso na caminhada de um bom profissional;

i) ter persuasão: é a capacidade de convencer os outros, não para tirar proveito das situações, mas para a obtenção da melhoria na qualidade empresarial.

Ribeiro (2005) relata que o secretário executivo utiliza, além das técnicas secretariais, ferramentas de motivação, liderança, comunicação, gestão, dentre outras, para o desempenho das suas funções. Por esse motivo, faz-se necessário conhecimento de algumas habilidades técnicas, específicas e imprescindíveis para a atuação eficaz de um secretário, tais como: administração do tempo, planejar e organizar sua rotina diária; comunicação organizacional; responsabilidade e tomada de decisões e a logística que irá garantir a realização de uma atividade específica. Quanto aos aspectos humanos, o secretário executivo deve "ter um total controle sobre suas emoções, suas atividades e a de seus subordinados" (Seiblitz, 1999, p. 32). Deve ser totalmente responsável, ter controle das suas emoções e de seus deveres e realizá-los da melhor maneira possível, para que não ocorram falhas.

O profissional de Secretariado Executivo necessita ter conhecimentos de gestão, finanças, linguística, ética, direito e empreendedorismo, dentre outras, que ampliam a vantagem competitiva das atividades, transformando os ativos intangíveis e tangíveis em uma prática que gere um ganho para a organização e credibilidade para o profissional (Ribeiro, 2005). Os artigos $4^{\circ}$ e $5^{\circ}$ da Lei 7.733/85 (modificada pela Lei 9.261/96), que regulamenta a profissão de Secretariado, definem as atividades e atribuições a serem realizadas por esse profissional da seguinte forma:

Art. $4^{\circ}$ - São atribuições do Secretário Executivo: I - Planejamento, organização e direção de serviços de secretaria; II - Assistência e assessoramento direto a executivos; III - Coleta de informações para a consecução de objetivos e metas de empresas; IV - Redação de textos profissionais especializados, inclusive em idioma estrangeiro; V - Interpretação e sintetização de textos e documentos; VI - Taquigrafia de ditados, discursos. Conferências, palestras de explanações, inclusive em idioma estrangeiro; VII - Versão e tradução em idioma estrangeiro, para atender as necessidades de comunicação da empresa; VIII Registro e distribuição de expedientes e outras tarefas correlatas; IX - Orientação e seleção da correspondência para fins de encaminhamento à chefia; X - Conhecimento protocolares. Art. $5^{\circ}$ - São atribuições do Técnico em Secretariado: I - Organização e manutenção dos arquivos de secretaria; II - Classificação, registro e distribuição da correspondência; III Redação e datilografia da correspondência ou documentos de rotina, inclusive em idioma estrangeiro; IV - Execução de serviços típicos de escritório, tais como recepção, registro de compromissos, informações e atendimento telefônico

(Lei n. 9.261, de 10 de janeiro de 1996).

Revista de Gestão e Secretariado - GeSec, São Paulo, v. 4, n. 2, p 25-47, jul./dez. 2013. 
Para o desenvolvimento das suas atribuições, ter dinamismo, espírito empreendedor, foco, ser agente facilitador e se colocar à disposição no que for necessário para o crescimento da organização completam o perfil do profissional de Secretariado Executivo como gestor (Ribeiro, 2005). Observa-se que as aptidões do profissional de Secretariado Executivo podem ser inseridas nos papéis e competências gerenciais definidos por (Quinn et. al., 2003).

As discussões atuais acerca do secretário executivo sinalizam para a sua atuação como gestor. Lasta e Durante (2008) afirmam que o profissional de Secretariado não tem mais aquele perfil de executor de tarefas, a evolução da profissão proporcionou um aumento de responsabilidades e um incremento de atitudes, antes jamais vivenciadas pelos profissionais, passando, então, a exercer funções criativas, com capacidade de opinar e decidir, preocupando-se, inclusive, com as pessoas. "Ainda é um negociador, programador de soluções, empreendedor, mostrando iniciativa, proatividade, comprometimento e participando em inúmeras atividades no ambiente de trabalho" (Lasta \& Durante, 2008, p. 54).

A visão do secretário como gestor requer o desenvolvimento de competências gerenciais. Sobre esse aspecto, Barros, Braga e Silva (2011) consideram que as competências gerenciais do secretário executivo envolvem o pensamento estratégico, capacidade de identificar oportunidade de crescimento, inovar e elaborar objetivos na organização; eles estão relacionadas à nova postura que esse profissional está assumindo nos últimos anos: empreendedorismo, tomadas de decisões, comunicação, trabalho em equipe, orientação para o cliente, inovação e criatividade, entre outras competências estão sendo inseridas na profissão de Secretariado Executivo. No entendimento de Lima e Cantarotti (2010) as competências secretariais abrangem negociações, gerenciamento de informações, funções gerenciais como planejamento, organização, controle e direção, gestão secretarial e comunicação.

\section{MÉTODOS E TÉCNICAS DA PESQUISA}

A metodologia utilizada neste estudo foi uma pesquisa bibliográfica, descritiva e pesquisa de campo. A pesquisa bibliográfica é aquela que:

Revista de Gestão e Secretariado - GeSec, São Paulo, v. 4, n. 2, p 25-47, jul./dez. 2013. 
[...] explica um problema a partir de referenciais teóricos publicados em documentos. Pode ser realizada independentemente ou como parte da pesquisa descritiva ou experimental. Ambos os casos buscam conhecer e analisar as contribuições culturais ou científicas do passado existentes sobre um determinado assunto, tema ou problema (Cervo e Bervian, 2002, p. 55).

Quanto à pesquisa descritiva, Vergara (2000, p. 47) argumenta que esta "não tem o compromisso de explicar os fenômenos que descreve, embora sirva de base para tal explicação". O que se observa é que a pesquisa descritiva mostra as características de determinada população ou ação realizada por esta população. A utilização da pesquisa descritiva: “Deverá ocorrer quando o propósito de estudo for descrever as características de grupos, estimar a proporção de elementos que tenham determinadas características ou comportamentos, dentro de uma população específica" (Fernandes \& Gomes, 2003, p. 8).

No intuito de se responder à problemática estabelecida realizou-se uma pesquisa de campo de natureza quantitativa que "caracteriza-se pelo emprego de instrumentos estatísticos, tanto na coleta como no tratamento dos dados" (Beuren, 2008, p. 92).

$\mathrm{O}$ instrumento de coleta de dados foi constituído de duas partes: a primeira parte apresentou questões que buscaram traçar o perfil do respondente e a segunda parte versava sobre o tema em questão. Esta etapa foi subdividida em blocos específicos sobre as atividades e competências gerenciais. A construção do instrumento, por parte das autoras, fundamentou-se nas características das competências gerenciais apresentadas por Quinn et al. (2003). Seguindo o exemplo de escalas que utilizam variações pares (e.g. Carvalho-Freitas, 2007) o instrumento foi do tipo Likert,variando de 1 a 6, no qual a legenda variava da seguinte forma: 1. Nunca; 2. Muito

raramente; 3. Às vezes; 4. Normalmente; 5. Frequentemente; 6. Sempre.

A pesquisa foi aplicada a 25 profissionais via correio eletrônico ou pessoalmente abordados por conveniência ou acessibilidade. Os critérios para delimitação da amostra foram: formação concluída ou em andamento em Secretariado Executivo; estar atuando na área secretarial e desenvolver atividades de gerenciamento.

A análise dos dados se deu por meio de estatística descritiva cujos dados foram representados em tabelas de distribuições de frequências. Para Field (2009) a distribuição de frequência é muito útil principalmente para avaliar as propriedades de um conjunto de valores verificando o escore que apresenta maior ocorrência.

\section{APRESENTAÇÃO E ANÁLISE DOS RESULTADOS}

Revista de Gestão e Secretariado - GeSec, São Paulo, v. 4, n. 2, p 25-47, jul./dez. 2013. 
Inicialmente, a pesquisa de campo focalizou o conhecimento do perfil dos participantes. Notou-se que 55\% dos participantes têm idade entre 26 e 34 anos, seguido de $25 \%$ entre 34 e 42 anos, $10 \%$ entre 18 e 26 anos e 10\% têm acima de 42 anos. Quanto ao sexo dos entrevistados, a maioria, representada por $95 \%$ dos participantes desta pesquisa, é do sexo feminino e $5 \%$ é do sexo masculino.

Em relação à escolaridade dos participantes, $50 \%$ já possuem especialização, $40 \%$ possuem nível superior e $10 \%$ possuem o superior incompleto. Os participantes afirmaram, em sua maioria representada por $35 \%$, que já trabalham na área há mais de cinco anos, seguidos de $30 \%$ entre um a dois anos, $25 \%$ de 3 a 4 anos, e 10\% menos de 1 ano. Cinquenta por cento dos entrevistados trabalham em empresa privada e os outros 50\% trabalham em empresa pública.

Em seguida, a pesquisa buscou identificar quais são as atividades gerenciais na atuação do secretário executivo. Essas atividades foram indicadas no questionário aplicado aos profissionais fundamentando-se nas proposições de Quinn et.al. (2003), obtendo-se os resultados abaixo.

Tabela 1 - Síntese das atividades gerenciais na atuação dos secretários executivos.

\begin{tabular}{|l|c|c|c|c|c|c|}
\hline Atividades gerenciais & $(1)$ & $(2)$ & $(3)$ & $(4)$ & $(5)$ & $(6)$ \\
\hline Participa da elaboração do planejamento da organizacao & $30 \%$ & $5 \%$ & $30 \%$ & $20 \%$ & $5 \%$ & $10 \%$ \\
\hline Participa da organização de métodos e processos de trabalho & $10 \%$ & $5 \%$ & $35 \%$ & $30 \%$ & $10 \%$ & $10 \%$ \\
\hline Organiza a realização dos trabalhos a serem desenvolvidos na área & $0 \%$ & $0 \%$ & $5 \%$ & $35 \%$ & $15 \%$ & $45 \%$ \\
\hline Participa da distribuição de atividades dos funcionários & $20 \%$ & $5 \%$ & $20 \%$ & $40 \%$ & $5 \%$ & $10 \%$ \\
\hline Supervisiona atividades de funcionários & $25 \%$ & $5 \%$ & $10 \%$ & $25 \%$ & $10 \%$ & $25 \%$ \\
\hline Desenvolve atividades de liderança & $15 \%$ & $5 \%$ & $15 \%$ & $30 \%$ & $15 \%$ & $20 \%$ \\
\hline Avalia o alcance dos objetivos e metas & $20 \%$ & $15 \%$ & $20 \%$ & $25 \%$ & $5 \%$ & $15 \%$ \\
\hline Acompanha a realização do planejamento & $15 \%$ & $15 \%$ & $10 \%$ & $25 \%$ & $15 \%$ & $20 \%$ \\
\hline
\end{tabular}

Fonte: Resultados da pesquisa (2012).

Revista de Gestão e Secretariado - GeSec, São Paulo, v. 4, n. 2, p 25-47, jul./dez. 2013. 
A partir das considerações de Quinn et al. (2003) pode-se perceber que as atividades realizadas pelos profissionais de Secretariado Executivo estão relacionadas às funções gerenciais: planejamento, acompanhamento e realização do planejamento; organização dos trabalhos a serem realizados na área de Secretariado, participação na distribuição de atividades dos funcionários, participação na organização de métodos e processos de trabalho; direção, desenvolvimento das atividades de liderança, supervisão de atividades dos funcionários e controle, avaliação do alcance dos objetivos e metas.

A seguir são apresentadas as opções que melhor descrevem as competências gerenciais utilizadas na atuação do secretário executivo, na visão dos participantes, conforme tabelas e considerações.

Tabela 2 - Competências gerenciais - papel de mentor e facilitador.

\begin{tabular}{|l|c|c|c|c|c|c|}
\hline Papéis Gerenciais/ Competências gerenciais & $(1)$ & $(2)$ & $(3)$ & $(4)$ & (5) & (6) \\
\hline Papel de mentor e facilitador & & & & & & \\
\hline $\begin{array}{l}\text { Ao desenvolver atividades com outras pessoas, procura identificar } \\
\text { as habilidades e a contribuição que cada um pode oferecer para a } \\
\text { organização. }\end{array}$ & $10 \%$ & $10 \%$ & $15 \%$ & $35 \%$ & $10 \%$ & $20 \%$ \\
\hline $\begin{array}{l}\text { É capaz de perceber como as emoções próprias afetam a si e aos } \\
\text { outros no ambiente de trabalho. }\end{array}$ & $0 \%$ & $0 \%$ & $5 \%$ & $10 \%$ & $40 \%$ & $45 \%$ \\
\hline $\begin{array}{l}\text { É capaz de transmitir o que sente e pensa no ambiente de trabalho. } \\
\text { Delega tarefas e responsabilidades permitindo que o funcionário as } \\
\text { realize como lhe parecer melhor. }\end{array}$ & $5 \%$ & $0 \%$ & $15 \%$ & $25 \%$ & $25 \%$ & $30 \%$ \\
\hline $\begin{array}{l}\text { Reconhece as realizações daqueles que desenvolvem atividades e } \\
\text { oferece feedback sobre as atividades delegadas. }\end{array}$ & $5 \%$ & $0 \%$ & $15 \%$ & $25 \%$ & $25 \%$ & $30 \%$ \\
\hline $\begin{array}{l}\text { Ao realizar atividades em equipe contribui para a organização das } \\
\text { atividades. }\end{array}$ & $0 \%$ & $0 \%$ & $15 \%$ & $35 \%$ & $25 \%$ & $25 \%$ \\
\hline $\begin{array}{l}\text { Realiza tarefas que oferecem desafios e oportunidades de } \\
\text { desenvolvimento. }\end{array}$ & $10 \%$ & $5 \%$ & $10 \%$ & $45 \%$ & $20 \%$ & $10 \%$ \\
\hline
\end{tabular}

Fonte: Resultados da pesquisa (2012).

Revista de Gestão e Secretariado - GeSec, São Paulo, v. 4, n. 2, p 25-47, jul./dez. 2013. 
Os papéis de mentor e facilitador pertencem ao modelo de relações humanas. Nesses quadrantes, as metas almejadas são: o comprometimento e a moral. Assim, é função do gerente ajudar cada um a desenvolver suas próprias habilidades, ao mesmo tempo, congregando essas individualidades únicas na construção do time, tendo, portanto, como foco o desenvolvimento tanto dos indivíduos quanto do grupo ou equipe (Picchia, 2012).

Observou-se que o desenvolvimento das competências pelos secretários executivos investigados no papel de mentor, a partir de Quinn et al. (2003) são: a compreensão de si mesmo e dos outros, desenvolvimento de atividades com as outras pessoas, buscando identificar as habilidades e a contribuição que cada um pode oferecer à organização; capacidade de perceber como as emoções afetam tanto o profissional quanto os outros; comunicação eficaz (capacidade de transmitir o que sente e pensa no ambiente de trabalho) e desenvolvimento dos empregados (delegar atividades e responsabilidades e reconhecer as realizações daqueles que desenvolvem atividades consigo oferecendo retorno). Ao atuar como facilitador os secretários investigados apontaram como principal competência a construção de equipes (realização de atividades em equipe contribuindo para a organização das atividades).

Tabela 3 - Competências gerenciais - papel de coordenador e monitor.

\begin{tabular}{|l|c|c|c|c|c|c|}
\hline Papéis gerenciais/ competências gerenciais & $(1)$ & $(2)$ & (3) & (4) & (5) & (6) \\
\hline Papel de coordenador e monitor & $10 \%$ & $15 \%$ & $25 \%$ & $20 \%$ & $15 \%$ & $15 \%$ \\
\hline Coordena atividades, projetos e/ou eventos. & $15 \%$ & $10 \%$ & $15 \%$ & $40 \%$ & $0 \%$ & $20 \%$ \\
\hline Coordena atividades de um ou mais funcionários. & $10 \%$ & $5 \%$ & $15 \%$ & $30 \%$ & $25 \%$ & $15 \%$ \\
\hline $\begin{array}{l}\text { Administra as informações recebidas por meio do pensamento } \\
\text { crítico. }\end{array}$ & $0 \%$ & $0 \%$ & $5 \%$ & $25 \%$ & $15 \%$ & $55 \%$ \\
\hline Procura levar as informações úteis em consideração. & & & & & \\
\hline
\end{tabular}

Fonte: Resultados da pesquisa (2012).

Revista de Gestão e Secretariado - GeSec, São Paulo, v. 4, n. 2, p 25-47, jul./dez. 2013. 
Como monitores, os gerentes devem saber o que se passa em sua unidade, determinar se as pessoas estão cumprindo as regras e averiguar se o setor está fazendo sua parte. O papel de monitor requer cuidado com detalhes, controle e análise. Como coordenadores, espera-se que os gerentes deem sustentação à estrutura e ao fluxo do sistema. As características comportamentais do coordenador incluem a organização, a coordenação dos esforços da equipe, o enfrentamento de crises e a logística (Picchia, 2012).

Considerando as competências gerenciais definidas por Quinn et al. (2003), os dados da pesquisa apontaram que os profissionais de Secretariado no papel de monitor têm como principal competência a administração de informações por meio de pensamento crítico, procurando levar as informações úteis em consideração. Com relação às competências relativas ao papel de coordenador, pode-se destacar o gerenciamento de projetos, visto que os profissionais destacaram a coordenação de projetos e/ou eventos, bem como o planejamento do trabalho ao coordenarem atividades de um ou mais funcionários.

Tabela 4 - Competências gerenciais - papel de diretor e produtor.

\begin{tabular}{|c|c|c|c|c|c|c|}
\hline Papéis gerenciais/ competências gerenciais & (1) & (2) & (3) & (4) & $(5)$ & $(6)$ \\
\hline Papel de diretor e produtor & & & & & & \\
\hline Elabora o planejamento das atividades secretariais. & $5 \%$ & $5 \%$ & $10 \%$ & $40 \%$ & $10 \%$ & $30 \%$ \\
\hline Participa da elaboração de objetivos e metas de trabalho em equipe. & $10 \%$ & $10 \%$ & $10 \%$ & $35 \%$ & $25 \%$ & $10 \%$ \\
\hline Contribui para o planejamento da organização. & $15 \%$ & $10 \%$ & $15 \%$ & $15 \%$ & $30 \%$ & $15 \%$ \\
\hline $\begin{array}{l}\text { Planeja e estabelece prioridades na realização das próprias } \\
\text { atividades. }\end{array}$ & $0 \%$ & $0 \%$ & $15 \%$ & $25 \%$ & $10 \%$ & $50 \%$ \\
\hline $\begin{array}{l}\text { Analisa regularmente a maneira como está utilizando o tempo no } \\
\text { ambiente de trabalho. }\end{array}$ & $5 \%$ & $0 \%$ & $5 \%$ & $15 \%$ & $30 \%$ & $45 \%$ \\
\hline $\begin{array}{l}\text { Ao desenvolver as atividades, procura identificar os problemas que } \\
\text { impedem o alcance dos objetivos e metas. }\end{array}$ & $0 \%$ & $0 \%$ & $5 \%$ & $25 \%$ & $35 \%$ & $35 \%$ \\
\hline Deixa-se preocupar, fascinar e envolver pelas atividades que realiza. & $0 \%$ & $5 \%$ & $10 \%$ & $25 \%$ & $5 \%$ & $55 \%$ \\
\hline
\end{tabular}


Fonte: Resultados da pesquisa (2012).

Os papéis de diretor e produtor pertencem ao modelo das metas racionais. Como diretores, os gerentes devem explicitar expectativas por meio de processos, tais como planejamento e delimitação de metas. Já os produtores são orientados para tarefas, mantêm o foco no trabalho e exibem alto grau de interesse, motivação, energia e ímpeto pessoal. $\mathrm{O}$ modelo de metas racionais tem como objetivos a produtividade e o lucro (Picchia, 2012).

No papel de diretor, a partir de Quinn et al. (2003), estão presentes na atuação secretarial o planejamento e organização relativos, principalmente, aos serviços de secretaria, já que, segundo os participantes, elaboram o planejamento das atividades secretariais e o estabelecimento de metas e objetivos relacionados ao trabalho em equipe, contribuindo também para o planejamento da organização.

Quanto ao papel de produtor, os dados denotam que na profissão de Secretariado é fundamental a competência, administração do tempo, do estresse e equilíbrio de demandas concorrentes. Sob esse aspecto, os participantes destacaram que analisam regularmente a maneira como estão utilizando o tempo no ambiente de trabalho; desenvolvem as atividades, procurando identificar os problemas que impedem o alcance dos objetivos e metas e procuram estabelecer prioridades na realização das suas próprias atividades.

Tabela 5 - Competências gerenciais - papel de inovador e negociador.

\begin{tabular}{|l|c|c|c|c|c|c|}
\hline Papéis gerenciais/ competências gerenciais & (1) & (2) & (3) & (4) & (5) & (6) \\
\hline Papel de inovador e negociador & & & & & & \\
\hline $\begin{array}{l}\text { Procura inovar os processos de trabalho por meio do pensamento } \\
\text { criativo. }\end{array}$ & $0 \%$ & $5 \%$ & $25 \%$ & $25 \%$ & $20 \%$ & $25 \%$ \\
\hline $\begin{array}{l}\text { Tem facilidade em conviver e contribuir para os processos de } \\
\text { mudanças organizacionais. }\end{array}$ & $0 \%$ & $0 \%$ & $20 \%$ & $35 \%$ & $5 \%$ & $40 \%$ \\
\hline $\begin{array}{l}\text { Contribui para a negociação de acordos e compromissos da } \\
\text { organização por meio da apresentação de ideias, sugestões e } \\
\text { opiniões. }\end{array}$ & $15 \%$ & $5 \%$ & $15 \%$ & $20 \%$ & $30 \%$ & $15 \%$ \\
\hline
\end{tabular}

Revista de Gestão e Secretariado - GeSec, São Paulo, v. 4, n. 2, p 25-47, jul./dez. 2013. 
Contribui para tomada de decisão em reuniões com pares e subordinados.

$20 \%$

$10 \%$

$20 \%$

$10 \%$

Fonte: Resultados da pesquisa (2012).

Os papéis de inovador e negociador pertencem ao modelo dos sistemas abertos. Os inovadores costumam ser visionários. Nesse papel, o gerente é encarregado de facilitar a adaptação e a mudança, identificar tendências significativas e tolerar as incertezas e os riscos. Os negociadores preocupam-se com a sustentação da legitimidade exterior e a obtenção de recursos externos, devem ter astúcia política, poder e capacidade de persuadir e influenciar (Picchia, 2012).

O papel de negociador envolve as seguintes competências gerenciais em Secretariado, fundamentando-se em Quinn et al. (2003): negociação de acordos e compromissos; contribuição por meio da apresentação de ideias e sugestões e opiniões para tomada de decisão em reuniões, com pares e subordinados. Quanto ao papel de inovador, foram destacadas as competências: pensamento criativo, ao buscarem a inovação dos processos de trabalho e convívio e gerenciamento da mudança, pois os secretários investigados afirmaram ter facilidade de conviver e contribuir para os processos de mudanças organizacionais.

\section{CONSIDERAÇÕES FINAIS}

A realização desta pesquisa pautou-se na observação do comportamento atual do secretário executivo, já que este está atuando nas organizações pelo seu conhecimento técnico, eficiente e eficaz, colaborando para o crescimento organizacional. A análise deste trabalho possibilitou o delineamento de algumas reflexões relativas às atividades e competências gerenciais na atuação secretarial.

O levantamento bibliográfico possibilitou a fundamentação teórica relativa à atuação do secretário executivo e às competências gerenciais. A pesquisa de campo permitiu a identificação das atividades de gerenciamento na atuação secretarial, relativas ao planejamento, organização, direção e controle, como: participar da elaboração e organização do planejamento da organização; organizar a realização dos trabalhos na área; participar da distribuição das atividades dos funcionários; supervisionar atividade de funcionários; desenvolver atividades de liderança; avaliar o alcance dos objetivos e metas e acompanhar a realização do planejamento.

As competências gerenciais utilizadas na atuação do secretário executivo envolvem, principalmente, a compreensão de si mesmo e dos outros, a comunicação eficaz, a construção

Revista de Gestão e Secretariado - GeSec, São Paulo, v. 4, n. 2, p 25-47, jul./dez. 2013. 
de equipes, a administração de informações por meio de pensamento crítico e a coordenação de projetos e/ou eventos. Estão presentes, ainda, na atuação secretarial: o planejamento e organização relativos aos serviços de secretaria; o estabelecimento de metas e objetivos relacionados ao trabalho em equipe; a administração do tempo e do estresse, além da contribuição nas negociações de acordos e compromissos, por meio da apresentação de ideias, sugestões e opiniões, para tomada de decisão em reuniões com pares e subordinados. Destacam-se, também, as competências relativas ao pensamento criativo ao buscarem a inovação dos processos de trabalho e convívio e gerenciamento da mudança.

Reflete-se, portanto que, na visão dos profissionais investigados, as competências gerenciais são utilizadas em Secretariado Executivo nas suas diversas responsabilidades, contribuindo para o alcance de objetivos e metas organizacionais por meio do desenvolvimento de atividades que envolvem o gerenciamento, participação no planejamento, na condução e estímulo às pessoas e no controle. Esse profissional vem superando grandes desafios e ampliando suas competências e seu campo de inserção, contribuindo efetivamente para o desempenho organizacional e, de forma significativa, para a efetividade da gestão dos serviços de secretaria e, consequentemente, para o alcance dos objetivos organizacionais. Denota-se que a discussão acerca da gestão em Secretariado requer a delimitação das suas atribuições e competências que envolvem o processo administrativo. Espera-se que os resultados desta pesquisa contribuam para os debates sobre a gestão secretarial, para que este conceito possa introduzir um olhar abrangente e sistemático neste ambiente, a fim de resultar em um incremento na formação dos profissionais, e em melhoria das condições e incentivos a futuras pesquisas nesta área de atuação.

Revista de Gestão e Secretariado - GeSec, São Paulo, v. 4, n. 2, p 25-47, jul./dez. 2013. 


\section{REFERÊNCIAS}

Aktouf, O. (1996). A administração entre tradição e a renovação. São Paulo: Atlas.

Barros, C. M. P., Braga, M. C. \& Silva, J. S. (2011). As competências gerenciais na atuação do Secretário Executivo no nível estratégico. Revista Expectativa, Paraná, (n. 1, pp. 91-106, 2011), Recuperado em 8 mar. 2013 de $<$ http://erevista.unioeste.br/index.php/expectativa/article/view/6096>.

Beuren, I. M (org.). (2008).Como elaborar trabalhos monográficos em Contabilidade: teoria e prática. São Paulo: Atlas.

Carvalho-Freitas, M. N. (2007). A inserção de pessoas com deficiência em empresas brasileiras: um estudo entre as concepções de deficiência, condições de trabalho e qualidade de vida no trabalho. Tese de doutorado. UFMG.

Cervo, A. L. \& BerviaN, P. A. (2002). Metodologia científica: para uso dos estudantes universitários (5a ed.). São Paulo: McGraw-Hill do Brasil.

Fernandes, L. A. \& Gomes, J. M. M. (2003, janeiro/junho) Relatórios de pesquisa nas Ciências Sociais: características e modalidades de investigação. Revista Contexto (vol. 3, n. 4, pp. 1-23), Porto Alegre. Recuperado em 10 jan. 2013, de <http://seer.ufrgs.br/ConTexto/article/view/11638/6840>.

Ferreira, A. B. de H. (2001) O minidicionário da língua portuguesa. (5a ed.) rev. ampliada. Rio de Janeiro: Nova Fronteira.

Field, Andy. (2009). Descobrindo a estatística usando o SPSS. Porto Alegre: ArtMed.

Fleury, M.T. L. \& Fleury, A.(2001) Construindo o conceito de competência. Revista de Administração Contemporânea - RAC, Rio de Janeiro , v. 2, n. especial,, pp. 183-196. Recuperado em 26 set. 2013 de http://www.scielo.br/scielo.php?pid=S141565552001000500010\&script=sci_arttext.

Gil, A. C. (2010). Como elaborar projeto de pesquisa (5a ed.). São Paulo: Atlas.

Lasta, A. \& Durante, D. G. (2008). A gestão secretarial no cenário organizacional contemporâneo. Secretariado Executivo em Revista, Passo Fundo, n. 4, pp. 49-65. Recuperado em 10 jan. 2013 
de http://www.upf.br/secretariado/download/revista-n4.pdf

Lei N. 7.377, de 30 de setembro de 1985. Dispõe sobre o exercício da profissão de secretário e dá outras providências. Brasília: Senado Federal. Recuperado em 10 jan. 2013 de < http://www.planalto.gov.br/ccivil_03/leis/17377consol.htm>.

Lei N. 9.261, de 10 de janeiro de 1996. Dispõe sobre o exercício da profissão de secretário e dá outras providências. Brasília: Senado Federal. Recuperado em 10 jan. 2013 de < http://www.planalto.gov.br/ccivil_03/leis/L9261.htm\#art1>.

Lima, T. F. \& Cantarotti, A. (2010) A formação e a construção de competências para a atuação do profissional de Secretariado Executivo: um estudo de caso em uma Empresa Júnior. Revista de Gestão e Secretariado (n. 3, pp.94-122). São Paulo. Recuperado em 8 mar. 2013 de <http://revistagesec.org.br/ojs-2.2.4/index.php/secretariado/article/view/17>.

Parasuraman, A. (1991). Pesquisa de marketing. São Paulo: Atlas.

Picchia, D. (2012). Competências gerenciais: caso de um hospital público. Debates Fundap. $\begin{array}{llllll}\text { Recuperado } & \text { em } & 16 & \text { jan. } & 2012 & \text { de }\end{array}$ http://www.fundap.sp.gov.br/debatesfundap/pdf/Gestao_de_Poi\%C3\%ADticas_Publicas/Compe t\%C3\%AAncias_Gerenciais.pdf.

Quinn, R. E., Faerman, S. R. \& Thompson, M. P. (2003). Competências gerenciais: princípios e aplicações. Rio de Janeiro: Elsevier.

Ribeiro, N. de L. A. (2005). Secretário: do escriba ao gestor (2a ed.). São Luis: Sosingra.

Richardson, R. J. (1999). Pesquisa social: métodos e técnicas (3a ed.). São Paulo: Atlas.

Seiblitz, V. M. de L. e. (1999). Supersecretária: o guia para a profissional que quer vencer na vida. São Paulo: Nobel.

Silva, J. S. da, Barros, C. de M. P. \& Barbosa, M. F. S. (2012, julho/dezembro) Fundamentação da gestão secretarial: um estudo bibliométrico. Revista Gestão e Secretariado (Vol. 3, n. 2, pp. 106-126),. São Paulo. Recuperado em 10 jan. 2013 de, <

http://revistagesec.org.br/ojs-2.2.4/index.php/secretariado/article/view/114/pdf_14>.

Teixeira, R. C. F. \& Teixeira, I. S. (1998). Desenvolvimento das habilidades gerenciais através da liderança para a qualidade. Recuperado em 16 jun. 2012 de <http://www.abepro.org.br/biblioteca/ENEGEP1998_ART075.pdf>

Vergara, S. C. (2000). Projetos e relatórios de pesquisa em administração (3a ed.). São Paulo: Atlas.

Revista de Gestão e Secretariado - GeSec, São Paulo, v. 4, n. 2, p 25-47, jul./dez. 2013. 